\title{
Searching for Methodology: Feminist Relational Materialism and the Teacher-Student Writing Conference
}

Mindy Legard Larson milarson@linfield.edu

Linfield College, USA.

Donna Kalmbach Phillips dphillips@pacificu.edu

Pacific University, USA.

\section{Abstract}

\begin{abstract}
Using feminist relational materialism as a theoretical map, this paper seeks to reimage traditional case study methodology through the use of diffractive methodology. Reading and writing data diffractively is to refuse to privilege teacher and student talk and to instead study how material-discursive practices intra-act as phenomenon. To do this, we developed questionsets based upon Barad's (2007) work to interrupt our habits of thinking in regard to a teacherstudent writing conference. These question sets provoke our thinking with data from fourth grade teacher-student writing conferences. We play with diffractive methodology highlighting one teacher-student writing conference as intra-activity. Experiencing the teacher-student writing conference again (and again) the question-sets diffract a response and a response diffracts the question-sets, calling us to a continuous becoming, an ethical consideration of how our research and teaching practices matter. We are left wondering if there is a methodology to search for or if methodology is an invitation to an ongoing performance, to join a dance of-theworld, in a constant making and re-making and wondering of what might be?
\end{abstract}

Key words: feminist relational materialism; teacher-student writing; diffractive methodology.

"Ethnographic designs," Creswell (2012) writes, "are qualitative research procedures for describing, analyzing and interpreting a culture-sharing group's shared patterns of behavior, beliefs, and language that develop over time. Central to this definition is culture" (p. 462). And culture is "everything having to do with human behavior and belief" (LeCompte, Preissle, \& Tesch, as cited in Creswell, 2012, p. 462). Everything having to do with human - and that is precisely the dilemma we faced.

Surely our study was "everything having to do with human." As literacy teacher educators we partnered with a fifth grade teacher in a rural, low-income school with a goal of improving writing through focusing on the teacher-student writing conference. With research (Calkins, Hartman \& White, 2006; Calkins, 2010) and professional experience, we felt confident that through the inquiry of the critical moments of human interaction found in the writing conference, we might develop case studies useful to teachers, teacher candidates, and student-writers. 
Although we had planned our fieldwork carefully and collected "thick data" in accordance with qualitative practices (Denzin \& Lincoln, 2011) when we came to data analysis, human shouted so loudly, demanding so much attention according to our habit of research thinking, according to the academic discursive practices subjecting our thought, we were limited in our understandings of what the children and teachers and ourselves as teacher educators/researchers were living. In the careful lines of transcripts, it was that which was in-between that refused to be ignored (Deleuze \& Guattari, 1980/1987), that which was excluded where possibility hid (Barad, 2007), it was the "matters of practices/doings/actions" (Barad, 2008, p. 122) that played across and around the language, the behavior, the matter in "culture" that came to matter: "Language matters. Discourse matters. Culture matters. There is an important sense in which the only thing that doesn't seem to matter anymore is matter" (Barad, 2007, p. 132).

We needed a methodological approach to look beyond culture-as-human, one that was not merely a tracing over always already charted territory, one that acknowledged how "the material and the discursive are mutually implicated in the dynamics of intra-activity" (Barad, 2007, p. 152). Our data included transcripts, field notes, memory stories, journal reflections and documented research discussions of teacher-student writing conferences in a grade five classroom. Such conferences are a mainstay of writing workshop pedagogy, an integral part of mentoring students as writers (Calkins et al., 2003). We wanted to read for the non-human in the data from these conferences, to read for the work of intra-action or the relationships between the human and non-human. We wanted to sever our data "from its traditional humanist orbit" (Barad, 2007, p. 177).

Mazzei (2010) writes, "Unless we push research and/or data (or theory for that matter) to its exhaustion, then we merely reproduce the original form - the colonized form if you will - limiting the voices to which we customarily attend in listening to our participants, circumscribing what 'counts' as data as that which is tangible, and inhibit our ability to make different sense of what has transpired" (p. 515). This is our attempt to "push" research, data, and theory towards exhaustion by exploring methodologies of intra-activity (Barad, 2008), a perspective that challenges the "anthropocentric gaze, a gaze that puts humans above other matter in reality..." (Hultman \& Lenz Taguchi, 2010, p. 526).

We began by asking of our teacher-student writing conference data, "What are the material forces at work? How do they play and operate? How do they change the identities of the humans and nonhumans?" In seeking an intra-active methodology or a methodology of intra-action, we developed a list of question-sets based upon Barad's (2007) work to provoke our thinking and seeing of the teacherstudent writing conference as a quantum leaps, which are not, "Jumps (large or small) through space and time.... [but] the intra-play of continuity and discontinuity, determinacy and indeterminacy, possibility and impossibility that constitutes the differential spacetimemattering of this world" (p. 182). Working through the question-sets, this kind of spacetimemattering became apparent: the poem-format used as writing prompt for students acted as a printed, tangible material entity, as apparatus, and intraacted with teacher and student during a writing conference and powerful discourses of school, each subjecting one another, each constructing one another. This is illustrated in one teacher-student writing conference highlighted in this paper between Mindy, one of the researchers, and David (pseudonym used), a grade five student.

To understand the question-sets and our emerging methodology, we first describe a theoretical mapping of feminist relational materialism. 


\section{A Theoretical Mapping}

Feminist relational materialism recognizes how the material and the discursive are mutually constitutive in their "intra-actions" (Barad, 1999, p. 2). In physics, intra-activity is the relationship between any organism and matter (human or non-human) that are understood not to have clear boundaries. Acknowledging intra-activity widens the perceived boundaries of case study methodology; agency no longer belongs to the human alone who acts upon non-human. Rather intra-activity is the "relationship between" and this relationship cannot be clearly delineated. Such entities are interdependent and entangled in a mutual relationship as a condition for their existence (Barad, 2007). This means that "Discursive practices and material phenomenon do not stand in a relationship of externality to each other; rather the material and the discursive are mutually implicated in the dynamics of intra-activity" (Barad, 2007, p. 152); they are "entangled" (Barad, 2007, p. 185). Acknowledging the intra-activity of the local context, culture, political discourses, the human and the nonhuman means that "identity is articulated with and by all others" so that the study of such intra-activity is a "comprehensive process, a process of comprehension, a material reality" (Kirby, 2008, p. 234).

Knowing, as intra-activity, includes the active participation of the material, which is often perceived from a humanist tradition as passive. Feminist relational materialism constitutes a shift from investigating the individual and their sociocultural relations, discourse and culture as the primary focus to the entanglement of the human and the non-human since "existence is not an individual affair" (Barad, 2007, p. ix.) This thinking re-situates the teacher-student writing conference not as an act between two humans, influenced by context, culture, political discourses and the material, but reimages the teacher, student and the material realities of the classroom as mutually active agents of intra-activity. With such a shift, the "subject can no longer be understood as a fixed being, but rather a 'way of being' - a verb rather than a noun. The subject is an effect of multiple encounters that entails the history of the previous encounters, the present and the potentialities of the future encounters that might take place" (Hultman \& Lenz Taguchi, 2010, p. 532). The "I" of the subject is not an isolated self, rather a collective of relationships, discourses, and the material, "The ' $\mathrm{l}$ ' spoke, but only as spoken by 'one' splattered across the social field" (Massumi, 1992, p. 34). The "I" of the teacher, the student, the pencil, the folded-paper, the writing prompt, the light of the projector - all moving verbs, subjects in flux, intra-acting, becoming.

This shift requires a refiguring of methodology in case studies, which traditionally places humans at the center of inquiry with an intent to analyze patterns of human behavior that can be generalized to other cases (Berg, 2004; Creswell, 2012). A feminist relational materialism approach viewing the subject as in motion, as a verb, or entangled in a web of discursive, cultural, political and material forces (Barad, 2007, 2008; Hultman \& Lenz Taguchi, 2010; Lenz Taguchi, 2010), results in data being "read horizontally as a juxtaposition rather than vertically as a hierarchy of being" (Frow, 2001, p. 283), disrupting "human" as the focus of data analysis. As researchers, we "listen closely for existential imperatives which, rather than limiting I and I's realm of virtuality, take it out of bounds" (Massumi, 1992, p. 41): out of bounds of common modes of coding, habitual thinking and from spaces of isolation.

Such thinking disrupts the case study of the teacher-student writing conference as an analysis of, for example, a two-way street of communication between teacher and student. Instead, we must search for ways to take the human "out of bounds," for ways to "see" intra-activity, the human and non-humans in-motion. We are no longer looking for patterns of human behavior. 
Rather, we are looking for diffraction, the "marking differences from within and as part of an entangled state" (Barad, 2007, p. 88). Haraway (1997) describes diffractive methodology as "a narrative, graphic, psychological, spiritual, and political technology for making consequential meanings" (p. 273).

Diffraction refers to a principle from physics concerning "the way waves combine when they overlap and the apparent bending and spreading out of waves when they encounter an obstruction" (Barad, 2007, p. 28). A methodology based upon diffraction is an accounting attentive to detail, an inquiry of differences and relationalities, a study of the phenomenon of how subject and object emerge as a result of intraactivity (Barad, 2007).

Diffractive methodology holds promise as a way to map the complexities of classrooms as spaces of diffraction, as the entanglement of bodies: the students, the teacher, desks, chairs, the intrusion of the intercom, the power of the clock, the authority of teacher's curriculum manuals, the demands of paper and pencil, the unseen presence and tyranny of achievement standards and mandated exams, all this entangled and overlapping as intra-action, as fractures of temporality. All of these kinds of human and non-human entities act as apparatuses or boundary-making entities, intra-acting, producing ontological becomings of expectations, rubrics, and writing made intelligible as "passing." Such apparatuses are not outside of a phenomenon but are themselves phenomena, fluid, changing, and part of the on-going intra-activity of the world (Barad, 2007).

The question becomes, "What emerges from the intra-activity of a teacher-student writing conference?" The goal of such a research question is not generalization but an illustration of the "very real consequences for how those bodies [human and non human] inhabit cultural space" (Hekman, 2008, p. 101). This cannot "be isolated to simple cause and effect relationship" (Lenz Taguchi, 2010, p. 137). Instead, we must focus on the phenomenon of the teacher-student writing conference, studying what is emerging from within the intra-activity of such an event, even while formulating new questions and problematizing practice. What is emerging is "uncodable, excessive, out-of-control, out-of category" (St. Pierre, 2002, p. 404) data: "we" as researchers/data; intra-acting, transforming as we (all) diffract, move, becoming-other (Deleuze \& Guattari, 1987) or "different from the present self" (Semetsky, 2006, p. 3). In this way, studying the phenomenon is a re-enactment and a re-embodied material-discursive ontological becoming, the composing of an assemblage, always, already changing. Emerging differently, we "plan and arrange pedagogical space in ways that were previously unimaginable" (Lenz Taguchi, 2010, p. 137).

How to begin such work? We turn to Barad (2007) to develop a method of mattering in our study of the teacher-student writing conference.

\section{A Methodology and a Method of Mattering}

\section{Context}

For this study, we partnered with two classroom teachers, in their third and fourth years of teaching. Two days a week for a six-week period, we conducted teacher-student writing conferences with children in grades four and five. Children in this rural school, located in the Western US, include those labeled as English language learners, Latino/a, Attention Deficit Hyper-Activity Disorder, and Asperger syndrome. The school is identified as Title One (a designation in the US for a school with over 40 percent of students receiving free or reduced lunch) with 80 percent of the students receiving free or reduced lunch. There is significant emphasis on having all children pass required exams in order to avoid federal 
sanctions under the then No Child Left Behind legislation. This is the primary reason the teachers and the principal agreed to our study: because the school needed to increase students' state writing scores from the $37.9 \%$ passing from the previous academic year. All children and their parents and guardians were informed of the study and our intent to analyze the audio-recorded teacher-student writing conferences. The informed consent was made available in both English and Spanish. Pseudonyms are used throughout in conformance with the informed consent.

Both classroom teachers' pedagogical approach to writing included the implementation of the writer's workshop as described by Calkins (2010). Writing workshop includes teacher-student writing conferences, one-on-one writing conversations to mentor students as writers. Calkins et al.'s (2003) work on the teacher-student writing conference is widely circulated among teachers in the US and includes the description of the "architecture" or four phases of a successful conference. Teachers begin each conference with research to determine the writer needs, move into a compliment phase, continue with a teaching point, and end the conference linking the teaching point to the next step the writer will take.

As teacher educators, we teach many of Calkins' (2010) writing strategies, including her approach to teacher-student writing conferences, in our literacy methods courses. In our own previous experiences as public school teachers, we practiced teaching writing through a workshop approach according to progressive literacy research (Graves, 1983; Murray, 1985; Myers \& Whitmore, in press). We and the classroom teachers agreed that an intervention strategy for improving student writing would be to focus on the student-teacher writing conference, providing more support and teaching to students through this one-on-one directed listening and teaching. We also agreed to focus on a poetry-writing unit as a way to increase student engagement and enjoyment of writing. Poetry is a way to invite play with words and images, a kind of "writing for fun." Poetry, we agreed, might serve as a way to energize studentwriters, before returning to more traditional forms of writing, including "test" writing.

The poetry-writing instructional period included a mini-lesson by the classroom teacher on a specific kind of poetry. Students had little exposure to poetry so the mini-lessons involved reading poetry and modeling poetry writing primarily through the use of mentor-texts, or a text that might provide a format and inspiration for students to follow. Thirty minutes of collaborative and individual writing followed the mini-lesson. During this time, Donna and Mindy, the researchers, and the classroom teacher would conduct writing conferences with individual students.

The mini-lesson presented on the day of the highlighted teacher-student writing conference in this paper is based upon the poem, "Where I'm From" by George Ella Lyon (1999) and popularized as writing pedagogy through the work of Linda Christensen (2001) who suggests its use can "invite the stories and voices of your students into the classroom" (p. 9). By celebrating the lives of students, the poem as critical pedagogy, is intended to support diversity and encourage pride in one's cultural and family heritage. Students study the poem under the mentorship of their teacher and then draft lists of items found in and around their home and related to their family representing where they are from and thus their identities. Finally, students write a poem using the Lyon's poem format with their own words and phrases from their own lives.

The teacher-student writing conference phenomenon highlighted in this paper is between one of the researchers, Mindy, and David (pseudonym), a fifth grade student. Consistent with feminist relational materialism, it is not so much that we chose our conference with David to document more in-depth or that David chose us; but rather our data analysis consistently demonstrated how Mindy, one of the two 
researchers, emerged differently based upon her entanglements with David. Lenz Taguchi (2010) notes that in studying classroom phenomenon or an event from a feminist relational materialism perspective, we don't want to "simply make a reading from the children's lesser valued position and give them voice" nor is it simply "taking a position of someone else, or trying to become the other, this is about reinstalling yourself in the event to become different in yourself, that is, to put yourself in a process of change and transformation to be able to experience the event differently" (p. 172). The documentation of this one teacher-student writing conference phenomenon allows us to put ourselves in this process of change and transformation, for, "If we change our gaze to the perspective of the materials, it becomes possible to see how the material realities can be understood to have agency in relation to what happens in the material-discursive intra-active processes taking place between the materials, the children and the students" (Taguchi, 2010, p. 35), we may experience the writing conference differently.

\section{"Data Sources"}

We place quotation marks around the subtitle, "data sources" to diffract the authorial notion of "data." Data is a loaded word when read from a feminist relational materialism perspective. Data are not the nuggets from which truth can be mined; data are moving, winding rhizomic points, thorns of provocation, places from where we choose to begin, but not the beginning - choose to begin in order to intra-act with data and data to intra-act with us. Data moving makes "analysis" impossible: data does not sit still so we cannot "take it apart" and "put it back together." We diffract data and our re-telling here is only one possibility; the retelling is an agential cut, an assemblage composed, temporal at best. What shall we describe as "data"? We might provide a map of the classroom to de-center the human-ist of our data; but see now, how the map appears static, objects as immovable, as something humans may bump into but not as making the human, not as intra-acting. This is our dilemma of committing "methodology" and "data" to the page. Our methodology is a thinking in-between, a becoming-other. Not all of this can play well in black and white.

So having given account of this, we proceed, asking the reader to imagine the following "data sources" roaming over and around the page: Our "data sources," as traditionally thought of in qualitative research, include digital recordings of writing conferences between teachers and the researchers and students; writing conference transcripts created from digital recordings; quantitative data such as scored student writing samples, scores from mandated state tests, and other school record data. We sketched a map of the room and used this as a reference in writing/recording field notes. After teaching sessions, we as researchers met and talked through the lesson and conferences of the day; these were audio-recorded. Later, as researchers, we would listen to these recordings and write our own reports of the day. As researchers we walked and talked about the teacher-student writing conferences in which we had engaged and this led to more writing and reading and talking and walking.

We also wrote memory stories, or perhaps a better term would be "composing assemblages" (Holbrook, 2013). Composing assemblages are stories of conferencing with writers that seemed to haunt us as researchers; these are the stories that pulled at us, insisted on changing us, as teachers of writing. Each version of the story is another assemblage, another agential cut, another diffraction with and of data. "The past is not some static being, and it is not a previous present, nor a present that has passed away; the past has its own dynamic being which is constantly renewed and renewing" (Colebrook, 2002, p. 77). Using the dynamic past, we wanted to disrupt our present, so we wrote and re-wrote these assemblages in multiple ways. We experimented writing in first person and third person, occasionally using narrative strategies such as magical realism to "hear" the story differently. We read the literature of feminist 
relational materialism and a reading would diffract our thinking and thus we revised the composing assemblage. We walked and talked and woke up late at night and would return to the stories, adding details and making references to what we were reading both in data and in the literature. The goal of writing, Deleuze says, is "becoming-imperceptible" (as cited in Bogue, 2004), to loose the intentional subject. This is not so much a deliberate move but an acknowledging that writing itself is intra-activity, that "Even when you think you're writing by yourself, it's happening with someone else who can't always be named" (pp. 11-12). Writing, as intra-activity, is our mode of inquiry (Richardson \& St. Pierre, 2005), and it keeps us reimaging, pastpresentfuture, serves as a provocation to think a difference (Deleuze, 1968/1994).

\section{Diffractive Methodology: Refiguring the Case Study as Intra-Activity}

Our methodological challenge was to practice reading and writing data diffractively refusing to privilege teacher and student talk and to instead study how material-discursive practices intra-act as phenomenon. To do this, we developed question-sets based upon Barad's (2007) work to interrupt our habits of thinking in regard to the teacher-student writing conference. In traditional qualitative studies and case study analysis, we might have read through transcripts and coded "the data" for themes, triangulating these themes with field notes, journals, and student work, with the intent of rendering a description of the student and how his writing improved (or not) through the course of the conferences. In an effort to break out of this apparatus of qualitative research, we used the question-sets based upon Barad's work, as an agential cut, as provocation, as a way to mark differences from within, to "see" the entangled ontology of the writing conference. We needed a way to see around the code, a way to wrestle free from words and things as separate, words as mirrors, "results" as representations. Rather we used the question-sets to set ourselves on a course of transformation, to accept that our practice as teacher educators, as "expert" teachers of writing, matter, that "the world is materialized differently through different practices" (Barad, 2007, p. 89). How do they matter? What diffractions intra-act, entangle? How are marks on bodies, differences, materialized? The question-sets enticed, plagued, and induced us to think and act with our practice, differently. And the question-sets changed as we intraacted with them and with the "data."

We are not suggesting that the question-sets act as a "methodology." We wrote them while reading Barad (2007) and allowed them to diffract our thinking, as a way to read and write, and write and read, and then "write something we might not have otherwise known" (St. Pierre, 2013). The questions-sets as intra-activity-query are diffractive motion, an instigation brewing.

We selected one composed assemblage and began to work with the question-sets based upon the composed assemblage. This working with the question-sets was long, indeed, at times, arduous. Our written responses circled back, wandered around, repeated itself - rhizomic writing. As researchers, we met and walked and talked about our thinking/writing, and then wrote again. We exchanged our "responses" to question-sets and using "track changes" wrote comments to each another, questioning, challenging, returning to Barad, and found ourselves getting lost in data and theory. Throughout this intra-activity, the question-sets, themselves, changed - they could not be static, but are movable as apparatuses. Following, then, are the question-sets as we last left them.

What apparatuses are enacted in the studied phenomena? Barad (2007) describes apparatuses as "the material conditions of possibility and impossibility of mattering; they enact what matters and what is excluded from mattering.... apparatuses are boundary-making practices (p. 148). Apparatuses are 
specific material-discursive practices. These question-sets act as apparatuses, determining boundaries on our data from the writing conferences and producing ontological becomings. Schools and classrooms; writing workshop pedagogy; the writing conference protocol; and a poem-format - these all act as apparatuses. "They [apparatuses] do not exist as static structures, nor do they merely unfold or evolve in space and time.... they are "material configurations or reconfigurings of the world" (Barad, 2007, p. 146). Because apparatuses are not static and are reconfigurings of the world, then it follows that as we reworked the question-sets, and the writing we did as a result of them, our thinking about the data changed and the data changed us. Apparatuses are "perpetually open to rearrangements, rearticulations, and other reworkings" (Barad, 2007, p. 170) making it impossible to "land" on a "theme" or "category" of "case study." Thus, the "focus" of the study spreads, and overlaps, and is diffracted. If our traditional case study began as a description of "a conference" and "how a writer develops through teacher-student writing conferences," then at one time it assumed an end point, the possibility of "results;" but as the apparatus diffracts, then who can know the outcome? Who can know "the results"? And now the "focus" leaks, disrupts and asks, "What and who emerges from the data?"

What are the discursive and material forces intra-acting within the phenomena being studied? What emerges through this intra-action? If the material is the discursive and the discursive is the material, then in studying a teacher-student writing conference, we analyze the intra-activity through studying the performance of bodies, meaning and knowledge. We study what comes to matter "through the world's iterative intra-activity" (Barad, 2007, p. 152). We acknowledge, then, that what we identify as coming to matter, is a material-discursive phenomena.

How are the past and the present enfolded in this moment of intra-activity? What knowledge and meaning as phenomena is produced? What are the consequences of exclusions and what possibilities do they create? Time is not a matter of sequestered units marching through a linear trajectory; past and present are not sequential. Barad (2007) uses the metaphor of tree rings, not to demonstrate time's march or a linear nature, but as a "witness [to] the effects of the external forces of change. Sedimenting is an ongoing process of differential mattering" (p. 181). Past and future are enfolded in the entanglement of intra-activity. Studying the teacher-student writing conference, then, we look for discontinuities, how boundaries are enacted and re-enacted, how habits of thinking exclude and produce and ask, "What possibilities do these create?"

What material consequences, the way we teach, relate, and care for children, (Lenz Taguchi, 2010) are produced based upon this data analysis? Having worked through the first four questions, we want to ask with our data, this important question. Lenz Taguchi (2010) explains this connection for us:

What we are engaged in, in pedagogical practices, can simply be understood as constituting habits - habits of teaching and learning that are tied to material-discursive conditions of things and matter, as well as ideas and notions of learning. Ideas and notions are of course also tied to socio-historical and political contexts. If we accept that pedagogical practices are a mixture of material-discursive phenomena actualised as habits of thinking and doing, what are the implications for practice? (pp. 49-50)

We are not studying the data to discern how to conduct the teacher-student writing conference better, or correctly; we are not trying to understand children as writers and how they are constructed as writers only; or analyzing talk as a stand alone; nor is it our goal to evaluate students' writing. We are looking for what "might be possible, what emerges, and what can become" (Lenz Taguchi, 2010, p. 177). 
How do we emerge differently (changed, transformed) as researchers, teachers of writing, teacher educators of literacy as we re-enact this experience through this data re-telling? Returning to Lenz Taguchi (2010), our attempt is to re-install ourselves in the event of the teacher-student writing conference to "become different" in ourselves. Through this act of returning to a teacher-student writing conference as phenomenon, how do we emerge? How are we changed, transformed? And, based upon this data analysis, "How might one live" (Lenz Taguchi, 2010, p. 178)?

We used these question-sets to spur diffractive thinking, to think a difference. "Diffraction involves reading insights through one another in ways that help illuminate differences as they emerge: how different differences get made, what gets excluded, and how those exclusions matter (Barad, 2007, p. 30). Hultman and Lenz Taguchi (2010) write,

A diffractive 'seeing' or 'reading' of the data activates you as being part of and activated by the waves of relational intra-actions between different bodies and concepts (meanings) in an event with the data. As you read, you install yourself in an event of 'becoming-with' the data." (p. 537)

We used the questions to play the data against each other, to push and enact new boundaries, to install ourselves with the data, because "what is 'inside' and what is 'outside' are intrinsically indeterminate" (Barad, 2007, p. 161).

\section{Thinking Data With Feminist Relational Materialism}

There is inherent unpredictability when teachers and students intra-act together with physical classrooms inside school buildings; the teacher-student writing conference is no exception. School writing in particular as it is materialized on paper, becomes the object of evaluation and assessment. Once words are written down, in the material-discursive context that is school, they become yet another material-discursive phenomena that would not exist otherwise. Now the writing is score-able. In formal assessments, evaluators employed by the State evaluate and score the writing using scientifically proven scoring guides. The pencil lead, scrawled on paper, is representative in the educational world of "success or failure." Identity as a writer stands with the materiality of the written form. Teachers bring with them their past, present and future, as do students to this act of writing, the expectations for, and the evaluation of school-writing.

Besides the material product of writing, there are the scaffolds, structures, mentor-text, the document projector, and teacher instructions that serve as apparatuses and boundaries for the writer. These, too, intra-act in the processes of becoming-writer. For example, the George Ella Lyon poem, "Where I am From" projected large onto the screen into the classroom of this study, beaming in bright white light, acts as apparatus, creating the tangible conditions of expectations, defining the poem students are to write, as "one just like George Ella Lyon wrote." The poem is full of warm memories (e.g., "I am from the dirt...black, glistening/it tasted like beets" and "I'm from He restoreth my soul/with a cottonball lamb/and ten verses I can say myself."), and materially-discursively communicates as it is projected on the wall of the classroom with the authority of published poet and the teacher to the student in bright white light, "Write a poem this way, a warm memory poem" with the assumption of child development expertise, "You must all have these kinds of warm memories." The projected poem-format, as pedagogical tool, works with and against the student's perceptions of poetry, confirming, disavowing, constituting what they might write with their discursively-thinking hands and label as poetry. 
The "Where I am from," poem intra-acts with the authoritative discourse of schooling and expectations, the classroom teacher's voice, and the material bright white light of the projector, becoming now poemformat, a composing assemblage to mold the thinking and writing of students, and this transforms again through diffraction as the teacher models writing such a poem and the poem-form diffracts with the teacher and the Lyon's poem materialized in bright white light beams across her eyes. All interconnected and interdependent in producing "poem-format," "poem," "teacher," and expectations of "student-writer."

The children of the classroom write down, at the teacher's direction, subheadings inferred from Lyon's poem: Toys I Love or Remember; Relatives; Family Sayings; Family Food Favorites. These headings, pencil-lead on paper, folded and thus divided into four equal squares, become yet another apparatus, creating boundaries, closing down and opening up possibilities for the would-be-poet, the would-bepoem, even as the apparatus that is the poem-form, changes again.

[The material presence of the projected poem-format; the physical act of children copying the subheadings on their paper; the pencils children grip, the paper folded, and the hands folding, the act of "writing," seeing lead materialized into the words, lead-words as bodies, that is to be their poem. Bodies squirming in chairs and bouncing on exercise balls, all working against and with each other: intraactivity.]

The classroom teacher announces it is writing time and students begin to work on their own "Where I am From" poem and Donna and Mindy, the researchers, and the classroom teacher move to conduct writing conferences with students.

[In traditional case study methodology, we would focus our attention now on what Mindy, the researcher, and David, the student, think and do. We would separate them as an "I" that can stand alone, as an "I" who can have a teacher-student writing conference, as human, and the poem-format, the blank page, and the projected white light as non-human, but "difference is a difference in relation to an identity - a difference to something - which is always the case in transcendent thinking" (Lenz Taguchi, 2010, p. 57). We pause in our analysis, in our thinking, diffracting the dominant ontology of transcendence: "we must instead focus on the whole of the learning event, including the environment and the agentic qualities of matter that intra-act with the learner" (Lenz Taguchi, 2010, p. 57). We begin again...]

The classroom teacher announces it is writing time and students begin to work on their own "Where I am From" poem. Mindy, David, the poem, the poem-format, materialized in the bright white light of the projector, the blank page, the hands folding the blank page, the blank page enfolding the hands, the kicking feet of children against desks, the vibrations between, the pencil held in a hand, the hand (the discursively formed hand) holding the pencil- all intra-act in a writing conference, all inter-connected, interdependent upon one another. Each will become anew, transformed, may become this, or that, or maybe this and that, "difference in itself rather than different in comparison to something else" (Lenz Taguchi, 2010, p. 58).

Mindy, close in with David; David bouncing, moving. David's friends sit near him; the desks are arranged in small square pods. His friends are already writing. But David moves the blank folded paper all over the desk and the blank folded paper moves David's hand across the desk. He taps the pencil, the lead: it doesn't write. The pencil molds his hands. The poem, the poem-format, the teacher's poem materialized in white bright light as authority, interrupted now by a student passing through its path. He (the many 
He's of David; the body that holds the marks of the He, becoming-he) says, "Could we write, like fake stuff"

Mindy, suggests a need for clarification, "A fake...friend?"

David eyes his friend, Luis, still playing with the paper, "No, I mean like stuff, like stuff that you like, you might get." As a material-discursive statement, it is impossible to trace the origins or to assume an origin. Has David held a friend's new soccer ball in his hands; felt reverberations of foot against a new soccer ball skin that produces thrill and desire? Perhaps the projected white light moved across his eyes producing a difference, another seeing of the image on the wall that is the poem to be followed? What past and future leaks into this present and the desire to write about "fake-stuff"?

Nano-seconds and Mindy needs to respond: Bright, white authorial light projects from the overhead: "Where I am From" (the word image is laden with critical pedagogy's discourse of "inviting students lives into the classroom"), collides with the next line, one from Lyon's poem, "I am from fudge and eyeglasses/from Imogene and Alafair," (as mentor-text) intra-acting with the classroom teacher's model poem, "I am from summer Sunday afternoons/picnics at the beach," (teacher model of poem) diffracting as "I am from ____ (complete with your own ideas)." The light, the material images of the words, the discourses intra-act with Mindy (and her subjectivity), each forming the other, the other forming: emerging expectations, "Mindy, make a teaching decision - teach." And, this, urgency dancing across the equally bright white of David's blank page, felt through the gyrations of the desk that is diffracting yet another student's kicking foot, intra-actions, producing bodies, blinding moment of possibilities and exclusions, all diffracting, all becoming, and, oh, in how many ways?

Mindy chooses to move on (she diffracts David's question in this way)...surely one of the headings will work, she is doing the research phase as Calkins (2010) suggests; she listens hard trying to find the teaching point. In this way, the architecture of a conference acts as apparatus, limits possibilities, creates its own agential cut, and, pointing to the words materially projected in bright white light, she says, "Okay, what could you write down next, David? What about relatives?"

David, turns the paper over so there is a blank side looking up, the side without the sub-categories. This intra-action, A David, turning the page over so the blank side is up; the paper turning David; David and the blank side of the paper refusing the subheadings, this marks an ontological shift, perhaps a refusal of the subheadings or perhaps it is the material presence of Lyon's poem inviting students' lives (whatever they are) "into the classroom" in ways not imagined by Mindy. The material presence of the subheadings is hidden; the material presence of the blank page emerges, intra-acting with David. This plural David replies, "I don't like any of my relatives. I don't know why. Could we write fake stuff?" The reply, not as isolate, "pure" human speech, but as a material-discursive phenomena, a diffraction of the covered subheadings and the projected poem in bright white light.

David's friends, Louis and Marvin, carry-on about "fake stuff." And Mindy (all of the materiallydiscursively constituted Mindys) has a dozen conversations in her head, one of which is interrupted by the Clock: time is running out and David has nothing on the Blank Page, only dangling subheadings, "I am from ___." Nothing. And the blankness in-between the subheadings matters: the blankness works with and against David, the poem-format, Mindy, (and more that is not written here). David may be required to stay in from lunch to finish at study hall; he won't be ready for tomorrow; he will be behind (again). What will the classroom teacher think of Mindy? Will she loose her "expert" status? Where can 
a blank page and dangling phrases travel? And the material presence of emptiness produces yet another ontological shift.

Mindy moves to another category. "How about this category? (She points to the projected subheading "Family Sayings" on the wall; then, turns over the paper, the paper turning her, and finger to materialized subheading, and subheading back to finger) and then she asks, "Does your dad have something he says a lot?"

[A pause here: data are moving too fast. We are swept up in the motion, in the physical/emotional/mental/spiritual act of reading. The material force of the subheadings projected onto the wall in bright white light produces Mindy's responses; acts as authoritative apparatus; structures the conference. "Mindy" is not human acting on her human rationale but Mindy as human is constituted by the projected authoritative subheadings. David writes the subheadings on the folded paper and these subheadings are transformed by pencil and David's discursively formed fingers even as "David" is constituted in the writing of the subheadings and their materializing before him as lead on paper. Differences are material and produce ontological shifts]

David says, "Shut up! My dad says, shut up!"

Louis and Marvin laugh. Then - David laughs. The desks move with the laughter and the squirming bodies; the clock moves with precise "time," the projected white bright light only appears steady and, then, it too moves as yet another body kicks the table on which it sits, diffracting light wildly across the bodies of the classroom (And who can see the difference this marks?) Marvin asks how to spell a name (a relief for Mindy to respond to such an objective question) and he tells about his father's saying, "Always judge people by how they dress. That's why," he says, "I can't wear baggy pants!"

Mindy now (quickly) must diffract David's comment. What possibilities exist? How does the poemformat image projected on the wall exclude possibilities and open up others? There is no projected poem about sad, or potentially abusive families where dads yell "Shut up!" The blank spaces of the folded paper require pencil-lead to paper, and phrases beginning with "I am from..." and where one is from, is not, a fake toy or dysfunctional family. (And what is "fake" and what is "real" is always already made intelligible through material-discursive practices of the Lyon's poem projected in white bright light.) A boundary has been set in place. David's question, "Could we write fake stuff?" transgresses the boundary of the poem-format, the expectations of school, of fifth grade boys, of the teacher-student writing conference. Multiplicities of possibilities and if the answer is "No, you may not write fake stuff," then poem-format cannot emerge differently, in this way, at this time, nor can Mindy or David.

The projected poem-format, as apparatus, appears to create a boundary that Mindy, in those tenuous moments of the conference, cannot trespass. She doesn't say, "Go ahead and write down the fake-stuff." Or, "If your Dad says 'Shut up' and this is what you want to write, write it down." The material-discursive of images of warm memories from the poem-format form a cold barrier of expectation of what fifth graders ought to write about.

The poem-format remains subheadings on a page, appearing static, yet each move with David's hand, the smudge of his fingerprints against the lined paper, is constituting David and Mindy and the poemformat. The responsiveness and resistance of the poem-format with all its agentic qualities holds possibilities but what those possibilities might become are different for every student, every teacherstudent conference as they are in relation to one another, every context that might be writing 
instruction. In this moment of intra-action, the material presence of empty spaces between the subheadings on paper become the ontological becoming of mattering.

The between spaces of blankness constitutes a thwarted Mindy, David, and poem-format. There is frustration, the tangible evidence of failure. They are stymied-in-the-moment the satisfaction of materialized words on a paper they might both recognize as "poetry," of receiving admiration from the classroom teacher - they can read the space between and feel how it writes, constitutes them. Furthermore, the poem-format as projected at this moment, appears stopped. "Learning thus often involves emotions, affections, lust, desire and imagination that we do not usually acknowledge" (Lenz Taguchi, 2010, p. 59). The empty spaces between the subheadings are writ with emotion, loss.

The ontological shifts of this teacher-student writing conference are produced through a collision of diffraction of the material and discursive. And this reading of the data is so narrow, excludes so much. The classroom on this day was filled with moving bodies: twenty-eight children, one teacher, two researchers; desks, chairs, exercise balls as chairs, pencils and papers; accounted and unaccounted for conversations; intercom interruptions; the clock; electronic dictionaries; pencil sharpeners; desires, fears, expectations, hopes, apathy, distractions and joy. No matter where we may focus our gaze, our gaze cannot be wide enough to encompass the inter-connectedness of beings, the intra-activity of the classroom.

\section{Searching for Methodology?}

And so when we asked ourselves, where has our search for methodology led us? What material consequences, the way we teach, relate, and care for children are produced based upon this diffracted data analysis? The analysis is difficult: in education, the view is always already upon the human. It is the human that receive a grade, a label, status, merit pay. But as Lenz Taguchi (2010) notes,

The challenge for pedagogy then is not to do away with the ' $I$ ', but to start thinking about how this ' $I$ ' is constituted in a total independence with, not just other 'I's but all that matters, artefacts and physical intensities and forces around it in the environment ...situated in a sociohistorical and geographical context. (p. 58)

In this diffractive analysis, Mindy and David and the poem-format are transformed through intra-action, material-discursive practices of schooling define the bodies of teacher, student and poems. If we widen our gaze and see this student-writing conference in the midst of the physical intensities and forces of the environment, we see the inter-connectedness of beings, the interdependence and emotions of classrooms. Through such awareness, we better honor the complexities of the learning and teaching and the place we call, "classroom."

Does this mean we have found a "new methodology" to replace all others? Does our search end here? If we have learned anything from feminist relational materialism it may be that "searches" do not end, rather they are becomings.

Lenz Taguchi (2010) writes, "learning from an onto-epistemological perspective takes place right in the middle of things, in our very living and doing pedagogical practices" (p. 61). Can research methodology be a verb without an end? Perhaps it is the search, the becoming right in the middle of things, partial illustrations of inter-connectedness of data flattened and re-imaged that evolves our research and writing conferencing practices. And so we ask, how we might be more present in the middle of things. 
"We need to plan very thoroughly and imagine possibilities of challenging intra-actions that might take place. We plan also in order to be able to diverge from our plan. We need to be on our toes..." (Lenz Taguchi, 2010, p. 61, italics added for emphasis).

Researching and conferencing on our toes, right in the middle of things.

We began this paper attempting to re-image case study methodology. Perhaps case study methodology does not need to be re-imaged; perhaps its possibility, like that of the teacher-student writing conference, lies in being undone. To "do" research and conferencing one must be "right in the middle of things." We plan a study, but we plan for diffraction, divergence, always already questioning our "meaning," as what has managed to make itself intelligible in that moment. Come back again and it will change. Is there a methodology to search for? (Can there be a methodology?) Perhaps methodology is an invitation to an ongoing performance, to join a dance with and of-the-world, in a constant making and re-making and wondering of what might be.

\section{References}

Barad, K. (1999). Agential realism: Feminist interventions in understanding scientific practices. In M. Biagioli (Ed.), The science studies reader (p. 1-11). New York, NY: Routledge.

Barad, K. (2007). Meeting the universe halfway: Quantum physics and the entanglement of matter and meaning. Durham, NY: Duke University Press.

Barad, K. (2008). Posthumanist performativity: toward an understanding of how matter comes to matter. In S. Alaimo, \& S. J. Hekman (Eds.), Material feminisms (p. 120-154). Bloomington, IN: Indiana University Press.

Berg, B. L. (2004). Qualitative research methods for the social sciences ( $5^{\text {th }}$ ed.). Boston, MA: Pearson.

Bogue, R. (2004). Deleuze's wake: Tributes and tributaries. Albany, NY: State University of New York Press.

Calkins, L. (2010). A guide to the writing workshop. Portsmouth, NH: FirstHand.

Calkins, L., Hartman, A., \& White, Z. (2003). The conferring handbook. Portsmouth, NH: FirstHand.

Creswell, J. W. (2012). Educational research: Planning, conducting, and evaluating quantitative and qualitative research, $4^{\text {th }}$ ed. Pearson: Boston, MA.

Christensen, L. (2001) Where I'm From: Inviting students' lives into the classroom. In B. Bigelow, B. Harvey, S. Karp \& L. Miller (Eds.), Rethinking our classrooms: Teaching for equity and justice (Vol. 2, p. 6-10). Williston, VT: Rethinking Schools.

Colebrook, C. (2002). Understanding Deleuze. Crows Nest, Australia: Allen \& Unwin.

Deleuze, G. (1994). Difference and repetition. Trans. Paul Patton. New York: Columbia University Press. (Original work published in 1968).

Deleuze, G., \& Guattari, F. (1987). A thousand plateaus: Capitalism and schizophrenia (B. Massumi, Trans.). Minneapolis, MN: University of Minnesota Press. (Original work published 1980). 
Denzin, N. K. \& Lincoln, Y. S. (Eds.). (2011). The Sage handbook of qualitative research (4 ${ }^{\text {th }}$ ed.). Thousand Oaks, CA: Sage.

Foucault, M. (2000). Interview with Michel Foucault. In Faubion, J. D. (Ed.), Power (p. 454-458). New York, NY: New Press. (Original work published 1980).

Frow, J. (2001). A pebble, a camera, a man who turns into a telegraph pole. Critical Inquiry, 28(1), 270285.

Graves, D. (1983). Writing: Teachers and children at work. Portsmouth, NH: Heinemann.

Haraway, D. J. (1997). ModestWitness@SecondMillennium.FemaleManMeetsOncoMouse: Feminism and technoscience. New York, NY: Routledge.

Hekman, S. J. (2008). Constructing the ballast: An ontology for feminism. In S. Alaimo, \& S. J. Hekman (Eds.), Material feminisms (p. 85-119). Bloomington: Indiana University Press.

Holbrook, T. \& Hundley, M. (2013, May). The perplexity of authoring in academia. Paper presented at the Ninth international Congress of Qualitative Inquiry, University of Illinois at Urbana-Champaign.

Hultman, K., \& Lenz Taguchi, H. (2010). Challenging anthropocentric analysis of visual data: A relational materialist methodological approach to educational research. International Journal of Qualitative Studies in Education, 23(5), 525-542.

Kirby, V. (2008). Natural convers(at)ions: Or, what if culture was really nature all along? In S. Alaimo, \& S. J. Hekman (Eds.), Material feminisms (p. 214-236). Bloomington, IN: Indiana University Press.

Lather, P. (1991). Getting smart: Feminist research and pedagogy with/in the postmodern. NY: Routledge.

Lenz Taguchi, H. (2010). Going beyond the theory/practice divide in early childhood education: Introducing an intra-active pedagogy. NY: Routledge.

Lyon, G. E. (1999). Where I'm from: Where poems are from. Spring, TX: Absey \& Co.

Massumi, B. (1992). A user's guide to capitalism and schizophrenia: Deviations from Deleuze and Guattari. Cambridge, MA: MIT Press.

Mazzei, L. A. (2010). Thinking with Deleuze in qualitative research. Journal of Qualitative Studies in Education, 23(5), 503-509.

Murray, D. (1985). A writer teaches writing ( $2^{\text {nd }}$ ed.). Boston, MA: Houghton Mifflin.

Myers, R. \& Whitmore, K. (in press). Reclaiming writing: Composing spaces for identities, relationships, and action. New York, NY: Routledge.

Richardson, L., \& St. Pierre, E. A. (2005). Writing: A method of inquiry. In N. K. Denzin, \& Y. S. Lincoln (Eds.), The Sage handbook of qualitative research ( $3^{\text {rd }}$ ed., p. 959-978). Thousand Oaks, CA: Sage Publications.

St. Pierre, E. A. (2013, May ). Refusing the "I" of collaboration. Paper presented at the Ninth international Congress of Qualitative Inquiry, University of Illinois at Urbana-Champaign. 
St. Pierre, E. A. \& Pillow, W. S. (Eds.). (2000). Working the ruins: Feminist poststructural theory and methods in education. New York, NY: Routledge.

Weedon, C. (1987). Feminist practice and poststructural theory. New York, NY: Blackwell. 